\title{
Advanced Testing Method for Ground Thermal Conductivity
}

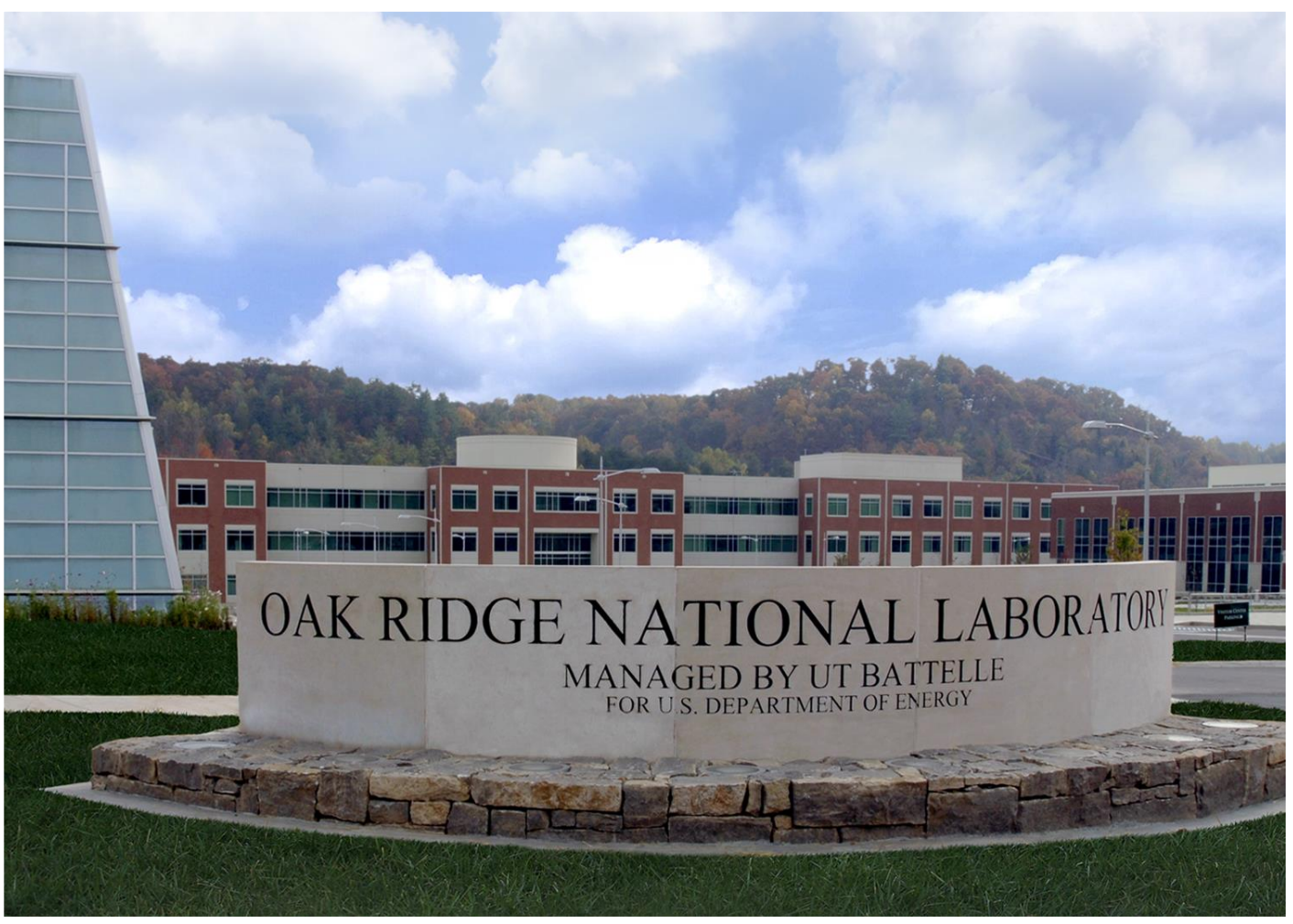

CRADA final report for CRADA number NFE-16-06144

Approved for public release. Distribution is unlimited.
Xiaobing Liu

Richard A. Clemenzi Liu Su

April 2017 


\section{DOCUMENT AVAILABILITY}

Reports produced after January 1, 1996, are generally available free via US Department of Energy (DOE) SciTech Connect.

Website http://www.osti.gov/scitech/

Reports produced before January 1, 1996, may be purchased by members of the public from the following source:

National Technical Information Service

5285 Port Royal Road

Springfield, VA 22161

Telephone 703-605-6000 (1-800-553-6847)

TDD 703-487-4639

Fax 703-605-6900

E-mail info@ntis.gov

Website http://www.ntis.gov/help/ordermethods.aspx

Reports are available to DOE employees, DOE contractors, Energy Technology Data Exchange representatives, and International Nuclear Information System representatives from the following source:

Office of Scientific and Technical Information

PO Box 62

Oak Ridge, TN 37831

Telephone 865-576-8401

Fax 865-576-5728

E-mail reports@osti.gov

Website http://www.osti.gov/contact.html

This report was prepared as an account of work sponsored by an agency of the United States Government. Neither the United States Government nor any agency thereof, nor any of their employees, makes any warranty, express or implied, or assumes any legal liability or responsibility for the accuracy, completeness, or usefulness of any information, apparatus, product, or process disclosed, or represents that its use would not infringe privately owned rights. Reference herein to any specific commercial product, process, or service by trade name, trademark, manufacturer, or otherwise, does not necessarily constitute or imply its endorsement, recommendation, or favoring by the United States Government or any agency thereof. The views and opinions of authors expressed herein do not necessarily state or reflect those of the United States Government or any agency thereof. 


\title{
Energy and Transportation Science Division
}

\section{Advanced Testing Method for Ground Thermal Conductivity}

\author{
Xiaobing Liu \\ Richard A. Clemenzi \\ $\mathrm{Liu} \mathrm{Su}$ \\ Date Published: \\ April 2017 \\ Prepared by \\ OAK RIDGE NATIONAL LABORATORY \\ Oak Ridge, Tennessee 37831-6283 \\ managed by \\ UT-BATTELLE, LLC \\ for the \\ US DEPARTMENT OF ENERGY \\ under contract DE-AC05-00OR22725
}

Approved for Public Release 


\section{TABLE OF CONTENTS}

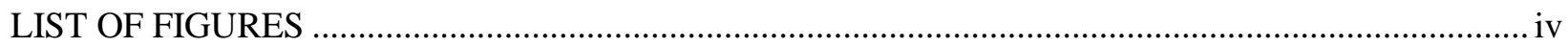

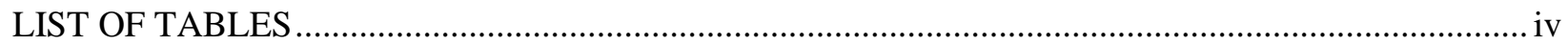

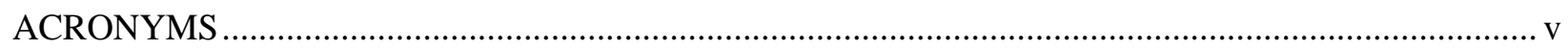

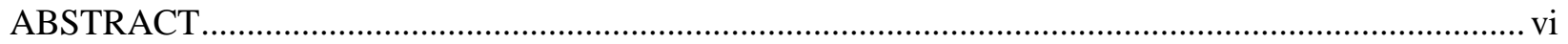

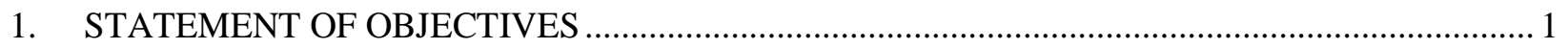

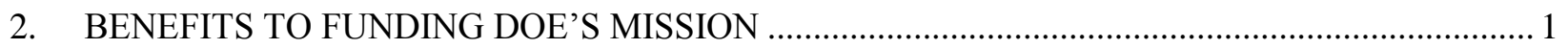

3. TECHNICAL DISCUSSION OF WORK PERFORMED BY ALL PARTIES …............................. 2

3.1 STATE-OF-THE-ART OF IN SITU GROUND THERMAL PROPERTIES TESTING.......... 2

3.2 EVALUATION OF A NEW METHOD FOR DETERMINING GROUND THERMAL

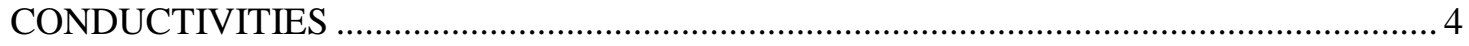

3.2.1 R-C Model for Transient Heat Transfer within a Borehole and Surrounding Ground Formation......

3.2.2 An Algorithm for Dynamically Determining Minimum TRT Duration ...................... 6

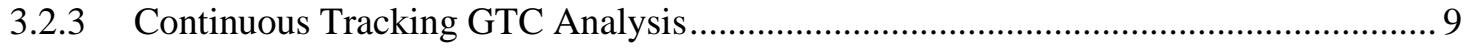

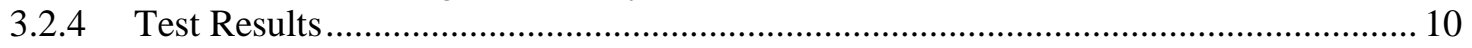

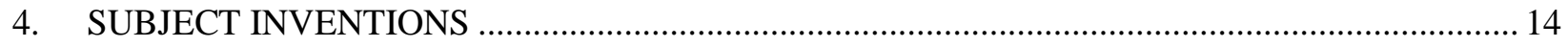

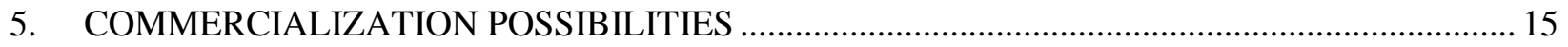

6. PLANS FOR FUTURE COLLABORATION

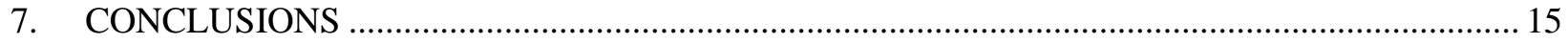

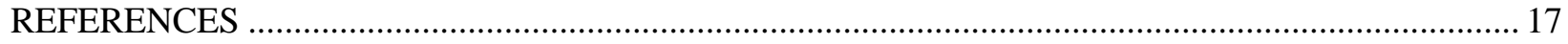




\section{LIST OF FIGURES}

Figure 1. Approximation of the geometry of a borehole with three different loops................................ 4

Figure 2. A circuit equivalent network of thermal resistance and capacity of each element of the R-

$$
\text { C model. }
$$

Figure 3. The procedure for determining GTC value with the R-C model................................................ 6

Figure 4. A flow chart of the new algorithm for determining the minimum test time of a TRT............... 7

Figure 5. GTC values determined dynamically with the new algorithm for 9 TRT cases.......................... 8

Figure 6. Continuous tracking GTC analysis (an example using TRT data of case 2)........................... 10

Figure 7. An example showing a good match between the predicted and measured fluid temperatures (case 2)

Figure 8 . An example showing ground thermal conductivity determined by three different methods (case 2).

Figure 9. An example showing the R-C model can be used to determine effective GTC with TRT data resulting from unstable heat input (case 3 ).

\section{LIST OF TABLES}

Table 1. A Summary of 9 TRT Cases..

Table 2. A summary of 12 TRT Cases and GTC Values Determined by the New R-C Model..... 


\section{ACRONYMS}

GDC Geothermal Design Center Inc.

GHEX ground heat exchangers

GHP geothermal heat pump

GTC ground thermal conductivity

ORNL Oak Ridge National Laboratory

$\mathrm{R}-\mathrm{C} \quad$ resistor-capacitor

RMSE root mean square error

TRCM thermal resistance and capacity model

TRT thermal response test 


\begin{abstract}
A new method is developed that can quickly and more accurately determine the effective ground thermal conductivity (GTC) based on thermal response test (TRT) results. Ground thermal conductivity is an important parameter for sizing ground heat exchangers (GHEXs) used by geothermal heat pump systems. The conventional GTC test method usually requires a TRT for 48 hours with a very stable electric power supply throughout the entire test. In contrast, the new method reduces the required test time by $40 \%-60 \%$ or more, and it can determine GTC even with an unstable or intermittent power supply. Consequently, it can significantly reduce the cost of GTC testing and increase its use, which will enable optimal design of geothermal heat pump systems. Further, this new method provides more information about the thermal properties of the GHEX and the ground than previous techniques. It can verify the installation quality of GHEXs and has the potential, if developed, to characterize the heterogeneous thermal properties of the ground formation surrounding the GHEXs.
\end{abstract}




\section{STATEMENT OF OBJECTIVES}

The effective ground thermal conductivity (GTC) is a highly critical parameter for designing a costeffective geothermal (ground source) heat pump (GHP) system. The current method for GTC testing is to impose an uninterrupted constant heat flux to a ground heat exchanger (GHEX) and determine the GTC based on the response of the fluid temperature of the GHEX to the heat flux, which is usually referred to as a thermal response test (TRT). Conventionally, TRT results are analyzed with a line source heat transfer model to determine the GTC using a reverse engineering method. This approach requires an extremely stable power supply throughout the entire TRT period (48 hours or more) — with variation less than $\pm 1.5 \%$ of the average value and peaks less than $\pm 10 \%$ of the average (ASHRAE 2015). This level of power supply stability is generally only available using a large diesel generator, which is expensive to rent and operate. In addition, the current industry standard requires a test duration of 36-48 hours, which is arbitrarily determined based on limited empirical data and lack of a strong mathematical and physical basis. This rigid requirement of an extremely stable power supply for 36-48 hours makes GTC testing relatively expensive (about $\$ 5 \mathrm{~K}$ ); consequently, it is rarely performed for residential GHP systems. The lack of accurate GTC data often leads to either oversized GHEXs, which make the already expensive GHP systems even more costly, or to undersized GHEXs that result in poor GHP performance and an unhappy customer. Further, the strict requirement for uninterrupted heat flux input leads to retesting delays of about 5 days in event of a power supply failure or interruption (to let the ground return to its neutral state). In addition, it foregoes any opportunity for verification of the GTC result using varying heat sources such as a building's operating heat pumps.

The objective of this study is to develop a new method that can determine GTC with comparable or better accuracy than the current state-of-the-art approach with a shorter test time and without a highly stable power supply for heat flux. Performance of this new method (i.e., accuracy and requirements for minimum test duration and quality of power supply) will be compared with the conventional method. Upon success, this new method could reduce the cost for GTC testing and help improve the design of GHP systems worldwide.

This new method was developed under a CRADA (No. NFE-16-06144) between Geothermal Design Center Inc. (GDC) and Oak Ridge National Laboratory (ORNL). Examples of TRT data and additional analysis were provided by Ewbank Geo Testing LLC, which built the first commercial field test unit and performed the first in-situ thermal conductivity test for the GHP industry in December 1994.

\section{BENEFITS TO THE FUNDING DOE OFFICE'S MISSION}

GHP is generally the most energy-efficient technology for providing space conditioning and water heating services to buildings. A recent assessment indicated that if $10 \%$ of U.S. homes were retrofitted with GHPs, 0.4 quad of primary energy can be saved, and 27 million metric tons of $\mathrm{CO}_{2}$ emissions could be avoided each year (Liu 2010). Similar benefits can be expected from GHP applications in commercial buildings (Hughes 2008).

The effective GTC value is a critical parameter for sizing the GHEXs. The current practice for determining a GTC value requires a TRT with extremely stable heat input for 36-48 hours, which is expensive and not affordable for many GHP projects, especially in the residential sector. The new method developed by this project can make GTC testing quicker and more affordable. With accurately determined GTC values, GHEXs can be properly sized and avoid the issues with undersized or oversized GHEXs. In addition, this new method can be used to verify the installation quality of GHEXs. These advancements can help improve the quality of GHP system design and facilitate the realization of the huge national energy saving potential of GHPs. As stated in DOE's Research and Development Roadmap for 
Geothermal (Ground-Source) Heat Pumps (DOE 2012), "Updated and more detailed geological data may reduce system cost by reducing initial cost estimate variability. Such data also enables analysis of regional difference and development of regionally optimized architectures."

\section{TECHNICAL DISCUSSION OF WORK PERFORMED BY ALL PARTIES}

To overcome the limitations of the line source model typically used to analyze conventional TRT results, GDC developed a new resistor-capacitor circuit (R-C) simulation model for the transient heat transfer process within a borehole and throughout the surrounding ground formation. In parallel, the ORNL team developed an algorithm to determine the minimum duration of a TRT at real time, and GDC extended this method to a more generalized tool to investigate GTC over time. GDC integrated the algorithms to create a new advanced method that can determine GTC with comparable accuracy to the current state-of-the-art. The new method also uses less than half of the test time, allows for a fluctuating or interruptible heat flux, performs a GHEX installation quality validation, and yields new insights into GTC that warrant further research.

\subsection{STATE-OF-THE-ART OF IN SITU GROUND THERMAL PROPERTIES TESTING}

The ORNL team conducted an extensive literature review to characterize the state-of-the-art of GTC testing, including data analysis algorithms, test apparatus, requirements, and limitations. The effective GTC along the depth of the borehole is usually determined by analyzing the TRT results of a vertical bore GHEX. To perform a TRT, a heat flux is rejected to or extracted from the GHEX for a certain period (usually 48 hours). The heat flux and the resulting fluid temperatures of the GHEX are collected during the test. The TRT captures the combined effects of various parameters that affect the heat transfer performance of the ground formation surrounding the GHEX, such as the thermal conductivities of different soils and rocks along the depth of the borehole and underground water movement.

The line source model has been the most widely used model for interpreting the TRT results. The original line source model was developed by Lord Kelvin (1882). Ingersoll and Plass first applied the model on GHEXs (Ingersoll and Plass 1948, Ingersoll et al. 1950). This model approximates the vertical borehole as an infinite line source and neglects the heat transfer at the ground surface and the end of the borehole. The ground is assumed to be an infinite medium with a uniform initial temperature. The heat conduction process is simplified as one-dimensional by neglecting the heat transfer along the borehole axis.

According to the line source model, the thermal response of the fluid temperature to a constant heat flux is expressed with Equation (1):

$$
T_{f}(t)-T_{0}=\frac{q}{4 \pi k} \operatorname{In}(t)+q R_{b}+\frac{q}{4 \pi k}\left(\operatorname{In}\left(\frac{4 \alpha}{r^{2}}\right)-\gamma\right),
$$

where, $T_{f}(t)$ is the measured average temperature of the fluid in the GHEX at time $t, T_{0}$ is the undisturbed ground temperature, $r$ is the borehole radius, $\gamma$ is Euler's constant, $q$ is the heating/cooling rate per unit length of the line source, $R_{b}$ is the borehole thermal resistance, $k$ and $\alpha$ are thermal conductivity and diffusivity of the ground. This equation is only valid for time scales greater than $5 r_{b}^{2} / \alpha$ (Claesson and Eskilson 1988).

As can be seen from the above equation, the average fluid temperature resulting from a constant heat flux is linearly related to the natural logarithm scale of time. The GTC value can thus be determined from the slope of the linear relationship as expressed with Equation (2):

$$
k=\frac{q}{4 \pi m}
$$


where $m$ is the slope of the linear relationship between the fluid temperature and the natural logarithm scale of time.

This model has some limitations resulting from the simplification of the physics. First, it is incapable of modeling the transient heat transfer within the borehole. Second, any significant fluctuation in the heat injection/extraction rate invalidates the model as demonstrated by Austin (1998) and therefore the heat flux (usually provided with an electric resistance element) needs to be extremely stable. Following the current industry standard (IGSHPA 2015 and CSA/ANSI 2016), the relative standard deviation of electric power should be less than $\pm 1.5 \%$, and the peaks should be less than $\pm 10 \%$ of the average.

Generally, longer test times lead to more accurate thermal properties of the ground with higher confidence. However, it is leads to relatively higher costs for the TRT and a higher possibility of encountering external disturbances (e.g., fluctuation of heat input or heat loss above the ground due to loss of insulation). Therefore, obtaining an accurate value for the effective GTC with minimum test time is of practical interest. Nevertheless, the required test duration is usually specified as a range and remains a subject of debate in the literature. John Geyer (2009) suggested that the power levels and supply and return water temperatures should be sampled every 5 minutes for 40-48 hours. The American Society of Heating, Refrigerating and Air-Conditioning Engineers handbook for HVAC applications (ASHRAE 2015), however, suggested test data should be collected at least every 10 minutes for a duration of 3648 hours. Austin et al. (2000) suggested a test length of 50 hours. It may not be possible to suggest a single test duration for all TRTs since the thermal response of a vertical bore GHEX is affected by many factors, including the heat transfer within the borehole and the thermal conductivity of the surrounding ground formation. In addition, to use the line source model to accurately interpret the TRT data, at least 10-18 hours of the earliest data need to be discarded (i.e., "cutting time"). He (2012) conducted sensitivity studies on the influence of several factors (e.g., cutting time, test duration, fluid circulation flow rate, grout conductivity, and heterogeneity of ground) on the GTC determined using the line source model. The results demonstrated that reducing test duration while obtaining GTC results with acceptable accuracy is possible in certain cases.

Many attempts have been made to improve the line source model by approximating the physics more accurately. The finite line source model (Zeng et al. 2002) and cylinder source model (Ingersoll 1954) represent a vertical borehole with a line source with a certain depth and an infinite cylinder source, respectively. However, both models seem to be less appealing in practice because significant improvements in calculation accuracy have not been reported while increasing the complexity of the model and cost of computation. Moreover, since both models discard the intrinsic effects of heat transfer inside the borehole and they are all based on the assumption that heat flux is constant, they have the same stringent requirements on the power stability and test duration as the infinite line source model does. Another notable attempt is exploring a thermal resistance and capacity model (TRCM) approach, which has become a trend recently (Bauer et al. 2011, Pasquier and Marcotte 2012, De Rosa et al. 2014, Bauer et al. 2011, De Carli et al. 2010, Zerrella et al. 2011, Ruiz-Calvo et. al. 2016). TRCM represents the physics with electrical circuits containing multiple resistances and capacitances. By positioning those resistances and capacitances appropriately, the intrinsic heat transfer process can be captured. Consequently, TRCM has a great potential for handling varying heat flux and shortening TRT duration. However, there are few studies reporting the efficacy of using TRCM to determine effective GTC with TRT data. The methodology of combining 2-D or 3-D numerical models with a parameter estimation technique has also emerged owing to the advancement of computation capacity. A 12 hour TRT is reportedly enough to determine the GTC with acceptable accuracy using this approach if assumptions are appropriate (Bozzoli et al. 2012). The main downside of this approach, however, is the prohibitively expensive computation cost, e.g. expensive hardware/software and long computation time, which has prevented its wide spread application. Another challenge of this approach is that the same numerical model needs to be used in the GHP design and simulation program to accurately predict the GHEX temperature resulting from the heat 
extraction/rejection loads of the building with the determined GTC value. Given the complexity of the numerical models, it is usually not practical to integrate them within the GHP design and simulation program, which needs performing hourly simulations for multiple years.

\subsection{EVALUATION OF A NEW METHOD FOR DETERMINING GROUND THERMAL CONDUCTIVITIES}

\subsubsection{R-C Model for Transient Heat Transfer within a Borehole and Surrounding Ground Formation}

Borehole geometry and heat transfer process within it can be modeled in detail with the finite element or finite volume method, but this modeling approach usually will take significant computational effort. GDC has taken a different approach to model the borehole heat transfer. As shown in Figure 1, the geometry of a borehole with three different heat exchangers-(1-a) single U-tube, (1-b) double U-tube, and (2) coaxial (concentric pipe) is simplified with a limited number of thermal zones. The ground formation surrounding the borehole is modeled with a series of successive concentric rings expanding outward from the center of a borehole. For GHEX designs (1-a) and (1-b), the grout is modeled as two zones: one is inward from the U-tube to the center of the borehole, and the other is outward from the U-tube to the borehole wall. The dividing point for the "inner" and "outer" grout zones is approximately the center of each leg of the U-tube. For GHEX design (2), there is only one zone for the grout, which is the annular space between the outer surface of the concentric pipe and the borehole wall. The inner "Grout 1 " of the concentric-pipe bore configuration is eliminated, and all the heat input is transferred to the outer "Grout 2."

(1) GHEX Simulation Model - Multi-pipe Bore Configuration
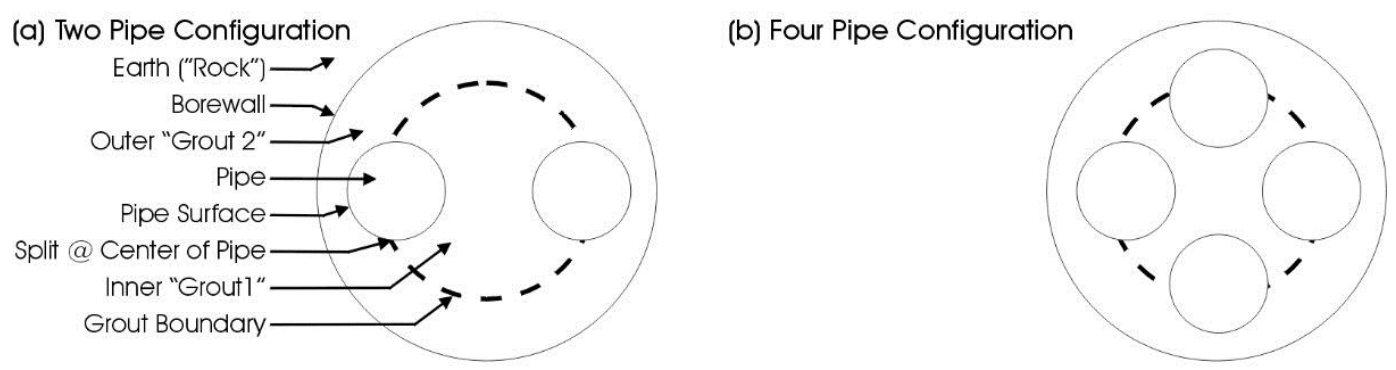

(2) GHEX Simulation Model - Concentric-pipe Bore Configuration

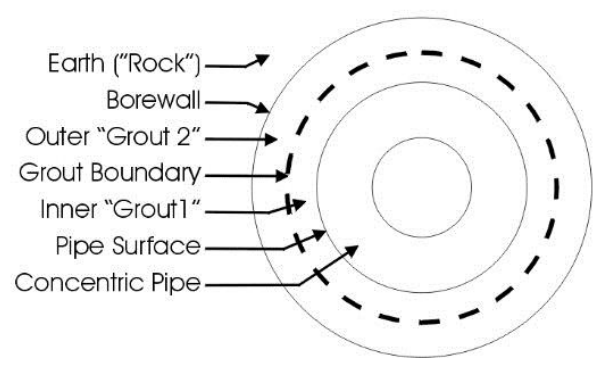

Figure 1. Approximation of the geometry of a borehole with three different loops.

The transient heat transfer inside the borehole and the surrounding soil is modeled with a circuit equivalent network of the thermal resistance (R) and the thermal capacity (C) of each major element (Figure 2). In this figure, lines indicate the heat flow paths, resistors correspond to the thermal resistance of each element, and capacitors correspond to the thermal capacity of the element. The thermal resistance and capacity of the U-tube(s) or the concentric pipes is usually much smaller than that of the grout and the 
ground, so they are neglected in the depicted implementation of the model. In this model, heat is transferred from the pipe into both the "inner grout," which is represented by a capacitor (3) and a resistor (5), and the "outer grout," which is represented by another capacitor (4) and another resistor (6). Heat also transfers between the inner grout and the outer grout if they are not at the same temperature.



Figure 2. A circuit equivalent network of thermal resistance and capacity of each element of the R-C model.

The ground formation within a radius from the center of the borehole is modeled with a series of outward rings. Each ring has a width of about 0.1 inch and is represented as a cell with a single resistor (10) and a single capacitor (9) (Figure 2). The implementation of the model tested assumes that the ground formation within the simulation domain is homogeneous and has uniform thermal properties for simplicity, but dissimilar vertical layers can also be modeled. The resistance of each cell is determined by the thickness of the cell and the ground thermal conductivity. The capacity of each cell is determined by the volume of the cell, as well as the density and specific heat capacity of the ground formation. Well logs are used to determine the initial heat capacity ${ }^{1}$ for the ground, which is then refined as the model is run.

The model inputs include the amount of heat transferred into the ground from the pipe inside the borehole and the initial ground temperature as measured before adding heat flux. In each time step, the temperature change and heat transfer at each element inside the borehole and at each cell representing the ground formation within the simulation domain are calculated based on the thermal properties of the ground, the grout, and other installation specifications such as bore depth, bore diameter, and pipe size and design. Figure 3 shows the procedure for determining effective GTC with the R-C model. Operation of the model involves experimentally adjusting the unknowns until a best fit is determined between the actual experimental data collected in the TRT and the calculated data with the R-C simulation model. The "best fit" of unknowns is determined when the resulting root mean square error (RMSE) of the calculated data is less than a specified threshold. Early test termination is possible once a minimum amount of time has passed so that heat is flowing into the ground and the RMSE is sufficiently small.

\footnotetext{
${ }^{1}$ The ground heat capacity is estimated based on the ground formation described in the well (bore) drilling log and the heat capacity values of various types of soil and rock listed in Table 3.4, "Thermal Properties of Rocks at $77^{\circ} \mathrm{F}^{\prime \prime}$, and Table 3.3 for soils (e.g., sand backfill) in the book Ground-Source Heat Pump: Design of Geothermal Systems for Commercial and Institutional Buildings, which is authored by S. Kavanaugh and K. Rafferty and published by ASHRAE in 2014.
} 


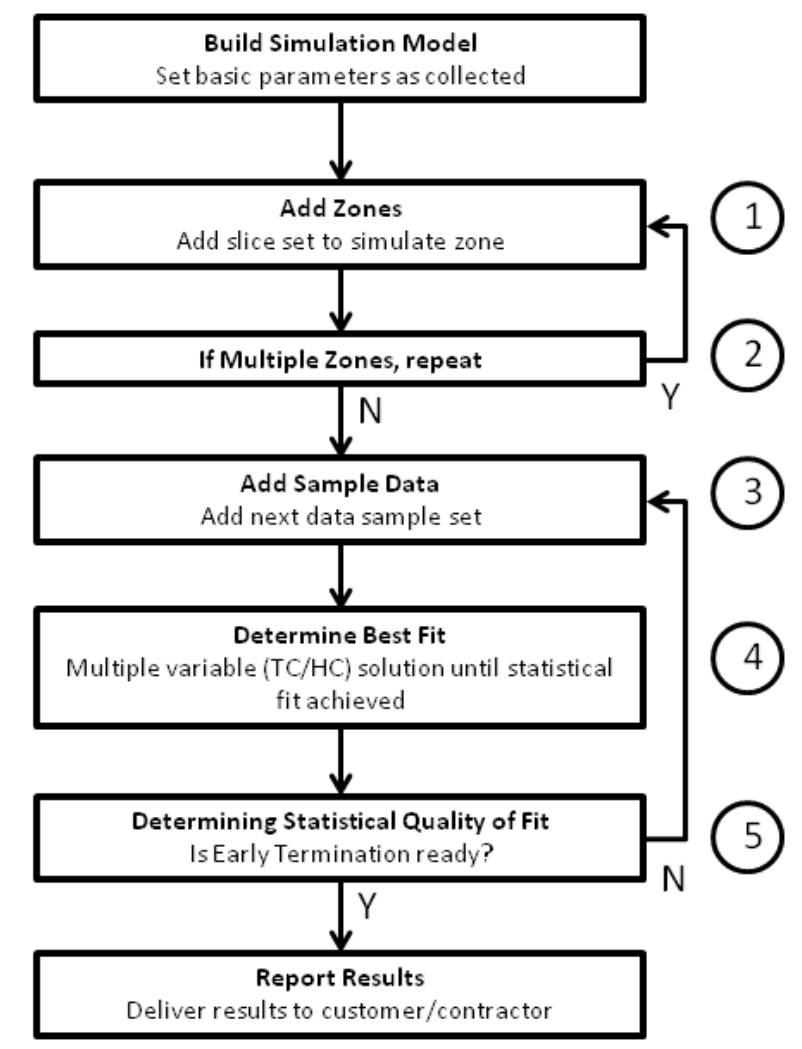

Figure 3. The procedure for determining GTC value with the R-C model.

\subsubsection{An Algorithm for Dynamically Determining Minimum TRT Duration}

A secondary algorithm was developed to dynamically determine whether a TRT has collected sufficient data to determine the GTC with acceptable accuracy. Figure 4 shows a flow chart for this algorithm. The step-by-step procedure of this algorithm is explained below:

1. Set the cutting time (e.g., 10 hour);

2. Evaluate GTC with TRT data at $1,2, \ldots$, and 10 hours after the cutting time using the line source method;

3. Calculate the relative standard deviation $\left(\varepsilon_{1}\right)$ and the relative variation $\left(\varepsilon_{2}\right)$ of the above calculated ten GTC values, and compare them with a set of criteria: $\left|\varepsilon_{1}\right|<1 \%$ and $\left|\varepsilon_{2}\right|<2 \%$;

4. If the criteria are satisfied, the TRT can be stopped and the 10th GTC value is reported;

5. If any of the criteria is not satisfied, go back to step 2 to evaluate GTC with the TRT data from the cutting time and the following $i+1, i+2, \ldots$ and $i+10$ hours using the line source method, where $i$ is the index of iteration. This process is iterated until all the criteria are satisfied or the total test time is more than 48 hours.

The relative standard deviation and relative variation $\left(\varepsilon_{1}\right.$ and $\left.\varepsilon_{2}\right)$ are calculated as expressed in equations (3) and (4), respectively:

$$
\varepsilon_{1}=\operatorname{std}\left(k_{i+j}\right) / \operatorname{mean}\left(k_{i+j}\right),
$$

and 


$$
\varepsilon_{2}=\left(\max \left(k_{i+j}\right)-\min \left(k_{i+j}\right)\right) / \operatorname{mean}\left(k_{i+j}\right),
$$

where $\operatorname{std}\left(k_{i+j}\right)$, mean $\left(k_{i+j}\right), \max \left(k_{i+j}\right)$, and $\min \left(k_{i+j}\right)$ are the standard deviation, mean value, maximum, and minimum values among the 10 calculated GTC values; $k_{i+j}$ is the GTC value evaluated with TRT data within various durations, and $j=1,2, \ldots, 10$.

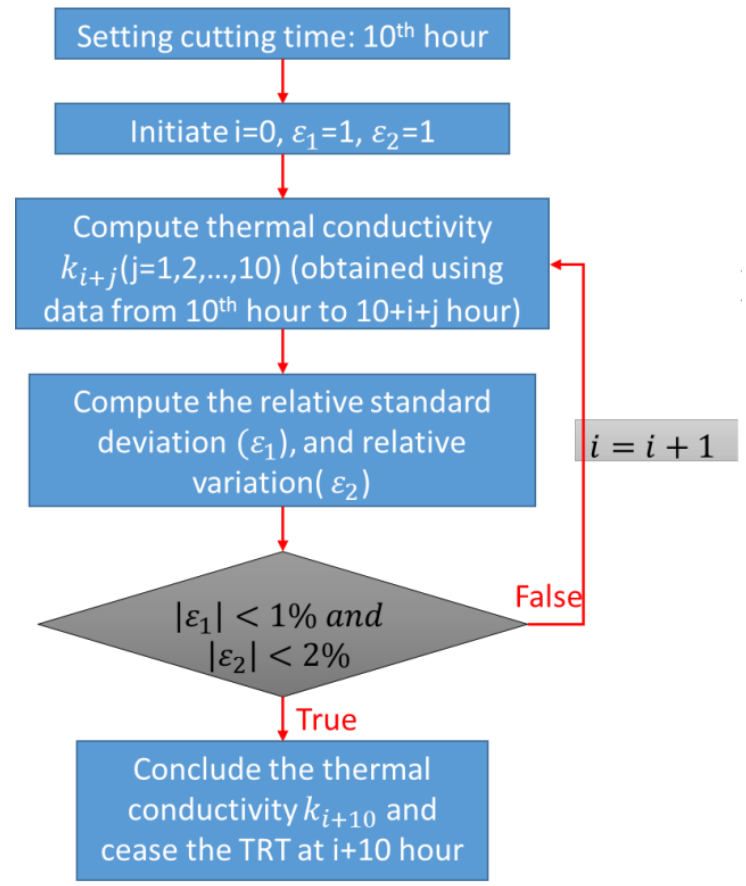

Figure 4. A flow chart of the new algorithm for determining the minimum test time of a TRT.

To implement this algorithm, a TRT needs to be continuously monitored, and the GTC value will be evaluated in real time using the available measured data from an ongoing TRT. The TRT can be concluded immediately when the progressively determined GTC values have converged (i.e., demonstrating satisfactory linearity between the fluid temperature and the natural logarithm scale of time).

This algorithm was applied to 9 TRT datasets ${ }^{2}$, and the GTC values determined with this new algorithm are compared with those determined using the conventional method. A summary of those TRT cases is shown in Table 1, and the validation results are plotted in Figure 5.

Table 1. A Summary of 9 TRT Cases

\begin{tabular}{|c|c|c|c|c|c|c|c|c|}
\hline Case & Location & $\begin{array}{l}\text { Borehole } \\
\text { diameter } \\
(\mathbf{m})\end{array}$ & $\begin{array}{c}\text { Grout thermal } \\
\text { conductivity } \\
\left(\mathbf{W} \mathbf{m}^{-1} \mathbf{K}^{-1}\right)\end{array}$ & $\begin{array}{c}\text { Depth } \\
\text { (m) }\end{array}$ & $\begin{array}{c}\text { Duration } \\
\text { (hour) }\end{array}$ & $\begin{array}{c}\text { Heat rate } \\
\left(\mathrm{W} \mathbf{m}^{-1}\right)\end{array}$ & $\begin{array}{c}\text { Measured } \\
\text { GTC } \\
\left(\mathbf{W} \mathbf{~ m}^{-1} \mathbf{K}^{-1}\right)\end{array}$ & $\begin{array}{c}\text { Undisturbed } \\
\text { ground } \\
\text { temperature }(K)\end{array}$ \\
\hline 1 & Brighton, $\mathrm{CO}$ & 0.1397 & $1.85-2.08$ & 184.4 & 43.6 & 84.04 & 2.01 & $285.1-288.8$ \\
\hline 2 & $\begin{array}{l}\text { Grand } \\
\text { Junction, CO }\end{array}$ & 0.1397 & 2.42 & 184.4 & 47.7 & 54.33 & 2.47 & $288.3-292.3$ \\
\hline 3 & Carlin, NV & 0.1334 & 0.74 & 80.8 & 41.4 & 63.27 & 2.28 & $287.1-289.7$ \\
\hline 4 & $\begin{array}{l}\text { Carson City, } \\
\text { NV }\end{array}$ & 0.1334 & 0.74 & 91.44 & 46 & 65.67 & 1.44 & $290.9-315.2$ \\
\hline
\end{tabular}

\footnotetext{
${ }^{2}$ TRT data at various locations were provided by Cary Smith in September 2016.
} 


\begin{tabular}{|c|c|c|c|c|c|c|c|c|}
\hline 5 & $\begin{array}{l}\text { Dugway } \\
\text { proving } \\
\text { ground, UT }\end{array}$ & 0.1334 & 0.74 & 67.1 & 40.9 & 63.17 & 1.02 & 286.1 \\
\hline 6 & Ogden, UT & 0.1334 & 1.61 & 106.7 & 43.5 & 60.58 & 2.96 & $286.3-287.3$ \\
\hline 7 & $\begin{array}{l}\text { Salt Lake City, } \\
\text { UT }\end{array}$ & 0.1334 & 1.90 & 128 & 44 & 66.63 & 1.76 & NA \\
\hline 8 & Bluffdale, UT & 0.1334 & 1.85 & 125 & 44 & 67.98 & 1.80 & $285.9-286.9$ \\
\hline 9 & Jackson, WY & 0.1334 & 0.69 & 108.2 & 41.6 & 60.19 & 2.27 & $283.2-284.0$ \\
\hline
\end{tabular}



Figure 5. GTC values determined dynamically with the new algorithm for 9 TRT cases.

In Figure 5, the black dots represent the GTC values progressively evaluated using the line source method (i.e., cutting time at 10th hour and using TRT data within certain time periods after the cutting time), and the green dots represent the minimum duration and the resulting GTC value determined by the new 
algorithm. The red dotted lines indicate the GTC values determined using the full (about 48 hours) TRT dataset with the conventional line source method; and the blue and green dotted lines indicate GTC values $5 \%$ higher and 5\% lower than the GTC values determined with the conventional method. Figure 5 shows that for all the test cases except case 3 a $21 \%-46 \%$ cut in the test time can be achieved while retaining the GTC value within $\pm 5 \%$ uncertainty of that determined with the full TRT dataset. It turns out that the power supply in case 3 was instable, thus the line source model results are not valid. Further analysis indicates that the test time can be reduced by $40 \%-60 \%$ when the cutting time is set at 5 th hour.

As clearly shown in Figure 5, the trend of the GTC values evaluated at various durations is significantly affected by the ratio between the grout and ground thermal conductivity $\lambda\left(k_{\text {grout }} / k_{\text {ground }}\right)$. When the ratio is significantly less than 1 , the trend indicates the calculated GTC values increase almost linearly with the duration (i.e., the period between the cutting time and the last TRT data used to calculate the GTC) but the slope decreases with the increase of the duration, as shown in cases 4, 6, and 9; however, when the ratio is close to 1 , the trend depicts a flat line, as shown in cases 2 and 8 . When the thermal conductivities of the ground and grout are close to each other, a short TRT (less than 24 hours) is sufficient to determine GTC with acceptable accuracy.

\subsubsection{Continuous Tracking GTC Analysis}

A further secondary algorithm is developed to continuously track the effective GTC based on measured TRT data to (1) further refine determination of the correct GTC and (2) to uncover variations in GTC affecting the accuracy of its determination. The continuous tracking GTC algorithm involves calculating a time-moving slope of temperature versus the natural logarithm scale of time, with integral smoothing of the data sufficient to eliminate noise but not to eliminate any deviation of at least 20 minutes. This analysis is related to the above algorithm for determining when to terminate testing based on progressively determined GTC values. But, instead of using a progressively growing span of averaged data, the continuous tracking GTC analysis maintains the same span throughout the test period to highlight localized trends in the data instead of the overall trend.

Figure 6 shows the GTC values determined with the continuous tracking algorithm using the measured TRT data in case 2 and a 30-minute floating window referred as "Actual (30)". As can be seen in Figure 6 , the continuous tracking result (shown with orange diamonds) converges very quickly to the known GTC value indicated by the black line as early as hours 6-10. 


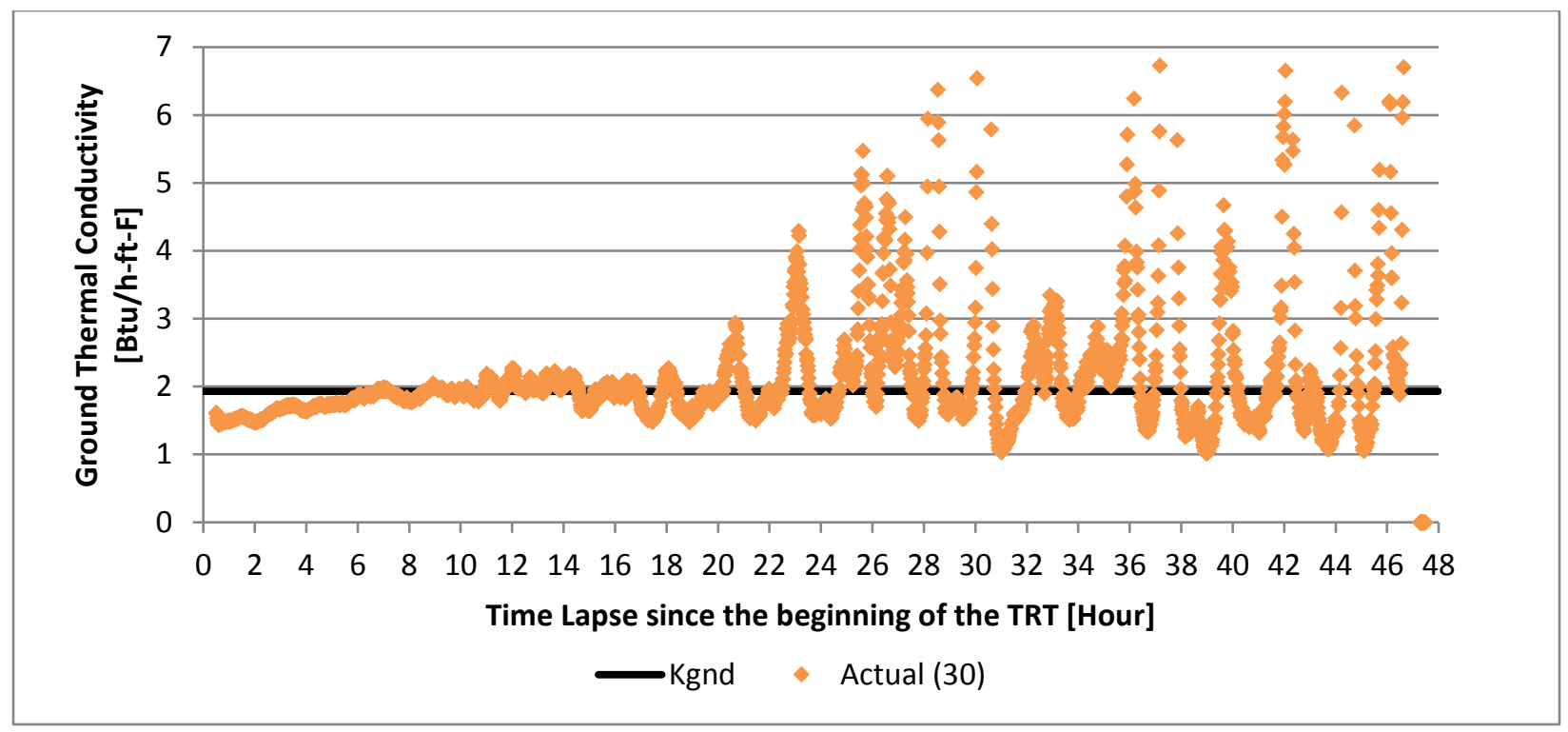

Figure 6. Continuous tracking GTC analysis (an example using TRT data of case 2).

A completely new result is depicted by the spikes of the continuously calculated GTC values seen from about 23 hour onward. The cause of these approximately $0.5-1$ hour long spikes in GTC is unknown at present. Possible theories include (1) ground water movement, and (2) phase change in ground formation moisture. Each of these possible phenomena cause short term increases in GTC, but they are quite different. The underground water movement theory can possibly lead to a smaller GHEX design (because the water movement can increase heat transfer in the ground and thus mitigate potential heat buildup in the ground after operating the GHEX for a long period), but the moisture phase change theory could be depicting a non-reversing one-time GTC improvement, which could result in a falsely high GTC result. Further research is needed to determine the causes of these spikes in GTC observed during the TRT.

\subsubsection{Test Results}

Full datasets for 12 different TRTs were collected $^{3}$, and each was performed for 36-48 hours at different vertical bore GHEXs. In addition, key parameters of the vertical bore GHEX tested were also collected, including loop design, bore depth, bore diameter, grout type, and undisturbed ground temperature. As listed in Table 2, these TRTs include various heat inputs (15-25 W/ft), GTC values $\left(1.2-2.2 \mathrm{Btu} / \mathrm{h}-\mathrm{ft}-{ }^{\circ} \mathrm{F}\right)$, bore depths (120-600 ft), grouting material (standard bentonite and various thermally enhanced grouts), and loop designs (single U-tube, double U-tube, and coaxial).

\footnotetext{
${ }^{3}$ TRT datasets were provided by Ewbank and Associates. Six of the TRTs were performed in July 2007 at 200 to
} 300 Block (east side) on N. Russell Perry, Oklahoma City, Oklahoma. 
Table 2. A summary of 12 TRT Cases and GTC Values Determined by the New R-C Model

\begin{tabular}{|c|c|c|c|c|c|c|c|c|c|c|}
\hline \multirow{2}{*}{$\begin{array}{c}\text { Case } \\
\# \\
\end{array}$} & \multirow{2}{*}{ Loop design } & \multirow{2}{*}{$\frac{\text { Depth }}{\mathrm{ft}}$} & \multirow{2}{*}{ Grout type } & \multirow{2}{*}{\begin{tabular}{|c|} 
Ground temp. \\
$\mathbf{F}$ \\
\end{tabular}} & \multirow{2}{*}{\begin{tabular}{|c|} 
Mea. Kgrd (LS) \\
Btu/h-ft- ${ }^{\circ} \mathrm{F}$ \\
\end{tabular}} & \multirow{2}{*}{$\frac{\text { Mea. Kgrd (RC) }}{\text { Btu/h-ft- }{ }^{\circ} \mathbf{F}}$} & \multirow{2}{*}{ Difference } & \multirow{2}{*}{\begin{tabular}{|c|} 
Rep. Kgrt \\
Btu/h-ft- ${ }^{\circ} \mathrm{F}$ \\
\end{tabular}} & \multirow{2}{*}{\begin{tabular}{|c|} 
Mea. Kgrt (RC) \\
Btu/h-ft- ${ }^{\circ} \mathrm{F}$ \\
\end{tabular}} & \multirow{2}{*}{ Difference } \\
\hline & & & & & & & & & & \\
\hline 1 & Co-axial (2.5" SDR-21) & 214 & Barotherm Max & 62.8 & 2.05 & 1.93 & $-6 \%$ & 1.79 & 0.80 & $-55 \%$ \\
\hline 2 & Single U-tube (1" DR11) & 319 & Barotherm Gold & 63.7 & 2.22 & 1.93 & $-13 \%$ & 1.00 & 0.99 & $-2 \%$ \\
\hline 3 & Double U-tube (1" PEX) & 260 & Barotherm Gold & 63.2 & NA* & 1.93 & NA* & 0.88 & 1.73 & $96 \%$ \\
\hline 4 & Co-axial & 120 & Barotherm Max & 63.0 & 1.85 & 1.92 & $4 \%$ & 1.60 & 0.42 & $-74 \%$ \\
\hline 5 & Co-axial & 150 & Barotherm Gold & 63.6 & 1.61 & 1.93 & $20 \%$ & 0.88 & 0.78 & $-11 \%$ \\
\hline 6 & Double U-tube (1" DR11) & 260 & Barotherm Gold & 63.4 & 2.08 & 1.93 & $-7 \%$ & 0.88 & 1.98 & $125 \%$ \\
\hline 7 & Single U-tube (1.25" DR11) & 600 & PowerTECx & 57.8 & 1.20 & 1.20 & $0 \%$ & 1.20 & 1.18 & $-2 \%$ \\
\hline 8 & Single U-tube (1.25" DR11) & 402 & Thermally enhanced & 67.4 & 1.55 & 1.55 & $0 \%$ & 1.00 & 1.32 & $32 \%$ \\
\hline 9 & Single U-tube (1.25" DR11) & 415 & Std bentonite & 64.8 & 1.64 & 1.64 & $0 \%$ & 0.41 & 1.01 & $146 \%$ \\
\hline 10 & Single U-tube (1.25" DR11) & 300 & Thermally enhanced & 65.4 & 1.75 & 1.75 & $0 \%$ & 1.00 & 1.29 & $29 \%$ \\
\hline 11 & Single U-tube (1.25" DR11) & 450 & Std bentonite & 56.4 & 1.88 & 1.97 & $5 \%$ & 0.41 & 1.09 & $166 \%$ \\
\hline 12 & Single U-tube (1.25" DR11) & 450 & Std bentonite & 56.9 & 2.06 & 1.97 & $-4 \%$ & 0.41 & 0.97 & $137 \%$ \\
\hline
\end{tabular}

Notes:

1. Barotherm Max is a mix of bentonite and graphite with an expected thermal conductivity of $1.6 \mathrm{Btu} / \mathrm{h} \cdot \mathrm{ft} \cdot{ }^{\circ} \mathrm{F}$.

2. Barotherm Gold is a mix of sodium bentonite and silica sand and has an expected thermal conductivity of 1.0 Btu/h.ft. ${ }^{\circ} \mathrm{F}$..

3. PowerTECX is an engineered alternative to silica sand and it can achieve thermal conductivities ranging from $0.79-1.60$ Btu/h.ft. ${ }^{\circ} \mathrm{F}$.

4. Kgrd in case 3 was not be able to be determined with the conventional line source method due to large variations of heat input.

GDC and ORNL determined GTC values using the new R-C model with each of the TRT datasets and compared the results with those of the conventional line source method. The comparison was conducted in three phases. In the first phase, the measured heat input of each full TRT dataset was used as input in the R-C model. The best-fit values of GTC and the thermal conductivity of the grout were determined by adjusting these values until RMSE of the predicted average fluid temperature is less than $0.1^{\circ} \mathrm{F}$ variation from actual measured values. Figure 7 shows an example of a good match between the measured and the predicted fluid temperatures. This example uses the TRT dataset of case 2, which has a stable heat input and detailed information about the GHEX being tested. It was found that, in a few cases, the bore depth or bore diameter are not consistent across various records of the same TRT, which indicates there are some uncertainties in these parameters. Therefore, the bore depth or bore diameter were slightly adjusted to get a good match between the measured and predicted fluid temperatures in these cases. Verification with a person directly associated with the TRTs suggests the adjustments were probably correct (G. Ewbank, pers. comm.).


Figure 7. An example showing a good match between the predicted and measured fluid temperatures (case 2). 
As shown in Table 2, GTCs determined with the new R-C model are very close to those determined with the conventional line source method (with less than $10 \%$ variance) except in cases 2 and 5. Thermal response tests for cases 1-5 were conducted in the same neighborhood (Hope Crossing at OKC), but the GTC values determined with the conventional line source method vary widely from 1.61 to $2.22 \mathrm{Btu} / \mathrm{h}$-ft${ }^{\circ} \mathrm{F}$. On the other hand, GTC values determined with the R-C model for these cases are consistent at 1.93 $\mathrm{Btu} / \mathrm{h}-\mathrm{ft}-{ }^{\circ} \mathrm{F}$, which is the average of the GTC values determined with the conventional line source method. It is not clear whether the actual GTC varies so widely at the same neighborhood (because of the different depths of the vertical bores) or if the variation is caused by a disturbance during the TRT (as discussed in the second phase tests).

The difference between the reported thermal conductivity values of the grout ("Rep. Kgrt") 4 and those determined with the R-C model ("Mea. Kgrt (RC)") are significant in most cases. For example, in case 3, Kgrt determined by the R-C model is $0.42 \mathrm{Btu} / \mathrm{h}-\mathrm{ft}-{ }^{\circ} \mathrm{F}$, which is $74 \%$ less than the reported value (1.6 $\mathrm{Btu} / \mathrm{h}-\mathrm{ft}-{ }^{\circ} \mathrm{F}$ ) for the Barotherm Max grout. However, in this case it was found the grout was pumped into the borehole from the ground surface instead of from bottom up as required because of the difficulty of grouting in this site. ${ }^{5}$ It is impossible to reliably grout the entire depth of the borehole from the ground surface. In this case, the bore did have water present, so the grout passing through that water would have far higher water content than required to achieve the specified thermal conductivity. It is also possible that some air gaps exist in the borehole above the water table. Together, these two issues explain the low effective thermal conductivity of that grout. All of the reported grout thermal conductivity values were either estimated based on grout type or through lab tests of grout samples. Even when properly pumped into a bore with a tremie from the bottom to the top of the bore, these values may be different from the effective thermal conductivity value in a borehole due to settlement and moisture change of the grout. This example indicates that the R-C model can more accurately determine the actual parameters that affect the heat transfer performance of a GHEX than the current practice and thus has the potential to identify quality issues of a GHEX installation. For cases 9-12, the grout type was unknown, and the reported grout thermal conductivity may not be correct. Another possible reason for the larger differences between estimated grout thermal conductivities may be the relatively coarse approximation of the pipe layout inside the borehole, especially for the double U-tube and the coaxial pipe (Figure 1). Some refinement of the pipe layout parameters in the model may be possible as more examples of each pipe configuration are tested.

A second phase of tests was performed with the new progressive line source method and continuous line source method (Sections 3.2.2 and 3.2.3). Figure 8 shows an example of the GTC values determined with the three methods using the TRT results in case 2 . The green line indicates the GTC value determined with the R-C model (utilizing only hours 4-20), the red line indicates the GTC values determined with the progressive line source method, and the blue diamond indicates the GTC values determined with the continuous tracking algorithm using a 30-minute floating window (referred as "Actual (30)"). The value of Actual (30) indicates the linearity of the relationship between the fluid temperature and the natural logarithm scale of time. As can be seen in Figure 8, the GTC values determined with the progressive line source method converged to the effective GTC value determined with the R-C model at 14th hour since the TRT started. The value of the Actual (30) varied widely from about 16th hour onward, which resulted in an increase of GTC values determined with the progressive line source method when TRT data in longer periods (than 14 hours) were used. This explains why the GTC value determined with the conventional line source method is significantly higher than that determined with the R-C model. This

\footnotetext{
${ }^{4}$ For cases $1-5$, the reported grout thermal conductivity value is the lab test result of grout samples collected from the blending tanks of the grout pumps before pumping into the borehole. The test was performed using the ASTM D 5334 (Standard Test Method for Determination of Thermal Conductivity of Soil and Soft Rock by Thermal Needle Probe).

${ }^{5}$ Per the field note provided by the contractor for grouting, "a progressive cavity pump was used to pump the grout. During pumping of the grout, the $3 / 4$ inch tremie line ruptured and was discarded. A 1 in. tremie line was installed but also ruptured, and grout was pumped into the bore hole from the surface."
} 
example indicates that the progressive line source method has the potential to shorten the time needed for TRT. It is not clear what caused the large variations of the fluid temperature in the latter TRT times. Because the electric power supply was very stable during this entire TRT, further investigation is needed to determine the cause of the large thermal conductivity variations measured (Section 3.2.3).



Figure 8. An example showing ground thermal conductivity determined by three different methods (case 2).

A third phase of testing was performed to evaluate whether the new R-C model can be used to determine effective GTC with TRT data resulting from varying heat inputs. The TRT for case 3 was performed with unstable heat input - sometimes at high heat, sometimes at low heat, and sometimes with no heat. This unstable heat input invalidates analyses using the conventional line source method. However, with the RC model, an effective GTC value can still be determined with these otherwise wasted data. As shown in Figure 9, the R-C model can accurately predict the fluid temperature resulting from the variable heat input profile, and the estimated GTC value using the R-C model is $1.93 \mathrm{Btu} / \mathrm{h}-\mathrm{ft}-{ }^{\circ} \mathrm{F}$, which is the average of the GTC values determined based on the good TRT datasets in several other locations in the same neighborhood. 


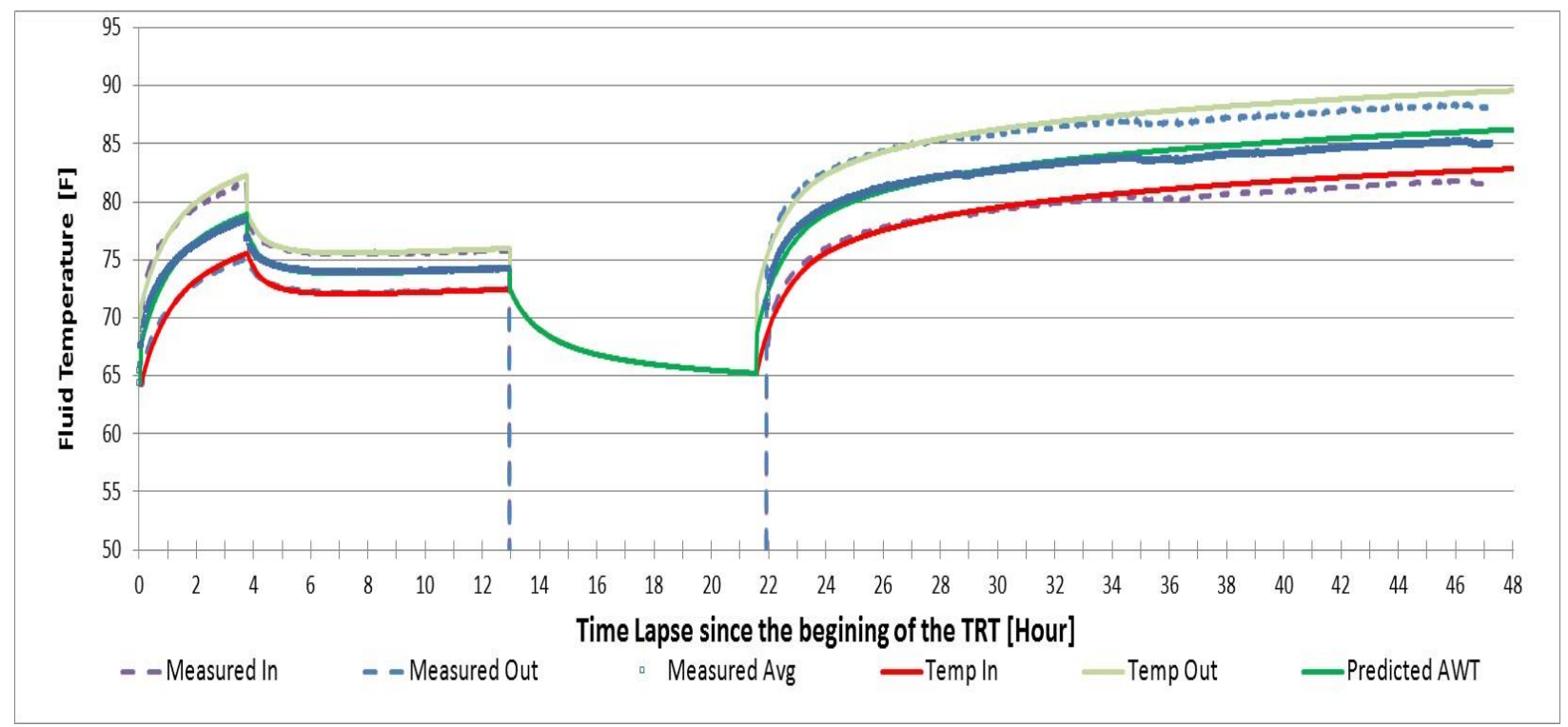

Figure 9. An example showing the R-C model can be used to determine effective GTC with TRT data resulting from unstable heat input (case 3).

Further, GTC values determined with the continuous tracking algorithm with the same dataset did show large spikes at hours $29,35,36$, and 39 , which strongly correspond to the downward deviations seen in the actual (blue) fluid temperature values versus those predicted by the R-C model (green). A planned integration of this newly discovered spike information into the R-C model will even further improve its accuracy.

\section{SUBJECT INVENTIONS}

The current effective GTC test is time consuming and expensive. It requires a TRT with extremely stable heat input for 36-48 hours. The GTC value is determined using a method depending on a single dimension curve fit (i.e., a straight line) between the average fluid temperature in response to a constant heat input and the natural logarithm scale of time. This method has several limiting factors, including (1) the TRT data collected during approximately the first $1 / 4$ of the test period must be discarded precluding evaluation of the heat transfer performance inside a borehole, (2) the lack of a mathematical approach for determining the cutting time before which the TRT data will be abandoned and the minimum test duration of a TRT, and (3) the vulnerability to any significant variation of the heat input.

The invention (PCT/US2017/023109 filed on 18-MAR-2017) developed through this study is a new method for determining GTC value. This new method can (1) dynamically determine when to terminate the TRT and can dramatically reduce the needed time of a TRT; (2) allow significant variation in heat input; and (3) empirically determine other key parameters of a vertical bore GHEX in addition to GTC (e.g., grout thermal conductivity, grout/ground thermal capacity, bore depth, and bore diameter). This method may also be able to identify heterogeneous thermal properties in the ground formation near the vertical bore and variations resulting from the underground water movements.

This new method is based on an R-C model for the transient heat transfer inside a borehole and through the surrounding ground formation. It uses an algorithm to dynamically determine the minimum duration of a TRT. It uses a multidimensional optimization approach to determine the effective GTC and other key parameters of a GHEX based on TRT data. 
By shortening the test time, eliminating the requirement for extremely stable electric power supply, or both this new method enables a much lower cost GTC determination capability, which may be further developed for post-installation determination of the same for a fully installed vertical bore GHEX using building operational data. By eliminating the "high quality electric only" heat input requirement of current GTC test methods, a large diesel generator is not a necessity any more for the TRT, which reduces fuel use and cost. Further, additional heat input sources can be used, such as direct fuel water heaters, solar water heaters, heat pumps, etc.

This advancement will increase the use of GTC testing and consequently will improve the quality of GHP system designs. Additionally, the new capability of post-installation GTC testing with varying thermal input opens a new door for GHP system analysis and validation, possibly leading to a new method for optimizing the operation of GHEXs in real time. GDC and Ewbank Geo Testing LLC have filed an international patent for these new testing methods.

\section{COMMERCIALIZATION POSSIBILITIES}

The new method developed in this project can make GTC testing quicker and more affordable to many potential consumers of GHP, including the residential sector. With accurately determined GTC values, GHEXs can be properly sized to avoid the expense of oversized GHEXs or the poor GHP system performance resulting from undersized GHEXs. In addition, the new method can be used to verify the installation quality of GHEXs. It will have significant market opportunity in regions where GHPs are becoming widely accepted, such as China, Sweden, and some parts of the United States. ORNL and GDC have identified a potential investor to help develop key overseas markets with a new device that uses the new method to test GTC and verify installation quality of GHEXs. Use of the new method for more thorough post analysis of TRT results is available now from GDC.

\section{PLANS FOR FUTURE COLLABORATION}

The real challenge to utilizing the new method of GTC testing is to modify the current standards to accept this new method. Both the International Ground Source Heat Pump Association standards (1B.3.1) and the ANSI/CSA C448 Standards (C448.3 subpart 4.5) currently require a minimum test duration of 36 hours and a stable power supply. GDC and ORNL will introduce this new method to the technical committees of the referred standards and further validate the new method with well-documented and verified TRT data.

In addition, the spikes in GTC values discovered by the new testing method need further investigation because they may be related to underground water movements or other changes of ground thermal properties experienced by the heat flow transferred from the GHEX. This heterogeneity in the ground may affect the effective GTC value determined from long periods of continuous heat flux into the ground. The direction and scale of this GTC variation should be further studied and determined. This information will be very useful for improving the prediction of the long-term performance of GHEXs, especially when the heat rejected to and extracted from the ground is not balanced on an annual basis, and this could lead to new methods of GHEX design. ORNL is seeking additional funding to investigate this issue.

\section{CONCLUSIONS}

A new method for testing GTC has been developed and evaluated. The new method is based on a R-C model for vertical bore GHEX developed by GDC and a new algorithm developed by ORNL for determining the minimum testing time. This new method can reduce testing time by $40 \%-60 \%$ compared with the current practice, and it retains the same level accuracy $( \pm 5 \%)$. It can reasonably estimate GTC 
value even with varying and disrupted heat inputs. The accuracy of the GTC value determined with this new method relies on the availability and accuracy of several key parameters of the installed GHEX, including borehole depth, borehole diameter, and grout thermal properties. This method can also be used to estimate other parameters of the GHEX, including grout conductivity and the heat capacity of the ground and the grout, to help verify whether the GHEX was installed following the design specification, and to improve GHEX design. In addition, this new method has the potential to detect underground water movement or other variances in the ground formation near a borehole. 


\section{REFERENCES}

American Society of Heating, Refrigerating and Air-Conditioning Engineers (ASHRAE). 2015. ASHRAE Handbook of HVAC Applications (2015 Edition).

ANSI/CSA C448 Series16. 2016 Design and Installation of Ground Source Heat Pump Systems for Commercial and Residential Buildings.

Austin III, W. A. 1998. "Development of an In Situ System for Measuring Ground Thermal Properties." Oklahoma State University.

Austin, W., C. Yavuzturk, and J. D. Spitler. 2000. "Development of an In-Situ System for Measuring Ground Thermal Properties.” ASHRAE Transactions 106(1): 365-79.

Bauer, D., et al. 2011. "Thermal Resistance and Capacity Models for Borehole Heat Exchangers. International Journal of Energy Research.” 35(4): 312-20.

Bauer, D., W. Heidemann, and H.-J. Diersch. 2011. "Transient 3D Analysis of Borehole Heat Exchanger Modeling." Geothermics 40(4): 250-60.

Bozzoli, F., et al. 2012. "Short-Time Thermal Response Test Based on a 3-D Numerical Model." In Journal of Physics: Conference Series. IOP Publishing.

Claesson, J., and P. Eskilson. 1988. "Conductive Heat Extraction to a Deep Borehole: Thermal Analyses and Dimensioning Rules.” Energy 13(6): 509-27.

De Carli, M., et al. 2010. "A Computational Capacity Resistance Model (CaRM) for Vertical GroundCoupled Heat Exchangers.” Renewable Energy 35(7): 1537-50.

Department of Energy. 2012. Research and Development Roadmap: Geothermal (Ground-Source) Heat Pumps.

De Rosa, M., et al. 2014. "Borehole Modelling: A Comparison between a Steady-State Model and a Novel Dynamic Model in a Real ON/OFF GSHP Operation.” Journal of Physics: Conference Series.

Geyer, J. D. 2009. "In-Situ Thermal Conductivity Testing for Ground-Coupled Heat Exchangers. Geothermal Resources Council Transactions," 33: 565-68.

He, M. 2012. Numerical Modelling of Geothermal Borehole Heat Exchanger Systems. De Montfort University, Leicester, UK.

Hughes, P. 2008. Geothermal (Ground-Source) Heat Pumps: Market Status, Barriers to Adoption, and Actions to Overcome Barriers. Rep. No. ORNL/TM-2008/232. Oak Ridge National Laboratory, Oak Ridge, TN.

International Ground Source Heat Pump Association (IGSHPA), 2015. Closed-Loop/Geothermal Heat Pump Systems Design and Installation Standards (2015 Edition).

Ingersoll, L., and H. Plass. 1948. "Theory of the Ground Pipe Heat Source for the Heat Pump." ASHVE Transactions 47(7): 339-48.

Ingersoll, L., et al. 1950. "Theory of Earth Heat Exchangers for the Heat Pump.” ASHVE Trans 56: 16788.

Ingersoll, L., O. J. Zobel, and A. C. Ingersoll. 1954. "Heat Conduction: With Engineering, Geological and Other Applications." 1954.

Kelvin, S. W. T., Mathematical and Physical Papers. 11. 1882, ff.

Liu, X., 2010. Assessment of National Benefits from Retrofitting Existing Single-Family Homes with Ground Source Heat Pump Systems. Rep. No. ORNL/TM-2010/122. Oak Ridge National Laboratory, Oak Ridge, TN.

Pasquier, P., and D. Marcotte. 2012. "Short-Term Simulation of Ground Heat Exchanger with An Improved TRCM." Renewable Energy 46: 92-99.

Ruiz-Calvo, F., et al. 2016. "Coupling Short-Term (B2G model) and Long-Term (G-Function) Models for Ground Source Heat Exchanger Simulation.” In TRNSYS. Application in A Real Installation. Applied Thermal Engineering. 102: 720-32.

Zarrella, A., M. Scarpa, and M. De Carli. 2011. "Short Time Step Analysis of Vertical Ground-Coupled Heat Exchangers: The Approach of CaRM.” Renewable Energy 36(9): 2357-67. 
Zeng, H., N. Diao, and Z. Fang. 2002. A finite line-source model for boreholes in geothermal heat exchangers. Heat Transfer-Asian Research, 2002. 31(7): p. 558-567 